\begin{tabular}{|l|l|}
\hline $\begin{array}{l}\text { 2. TO: (Receiving Organization) } \\
\text { DISTRIBUTION }\end{array}$ & $\begin{array}{l}\text { 3. From: (Originating Organization) } \\
\text { INTERIM STABILIZATION }\end{array}$ \\
\hline $\begin{array}{l}\text { 5. Proj./Prog.IDept./Div.: } \\
\text { INTERIM S'TABILIZATION }\end{array}$ & $\begin{array}{l}\text { 6. Design Authority/Design AgenUCog. Engr.: } \\
\text { W. F. ZUROFF }\end{array}$ \\
\hline
\end{tabular}

8. Originator Remarks:

ATTACHED IS AN ACCEPTANCE TEST PLAN (ATP) FOR THE NEW PUMPING INSTRUMENTATION AND CONTROL (PIC) SKIDS BEING FABRICATED BY SITE FABRICATION SERVICES.

11. Receiver Remarks: NONE
11A. Design Baseline Document? $O$ Yes $O$ No

\author{
4. Related EDT No.: \\ $\mathrm{N} / \mathrm{A}$ \\ 7. Purchase Order No. \\ $\mathrm{N} / \mathrm{A}$ \\ 9. Equip./Component No. \\ $\mathrm{N} / \mathrm{A}$ \\ 10. System/Bldg./Facility: \\ 241-U \\ 12. Major Assm. Dwg. No.: \\ $N / A$
}

13. Permit/Permit Application No:

$\mathrm{N} / \mathrm{A}$

14. Required Response Date $12 / 14 / 99$

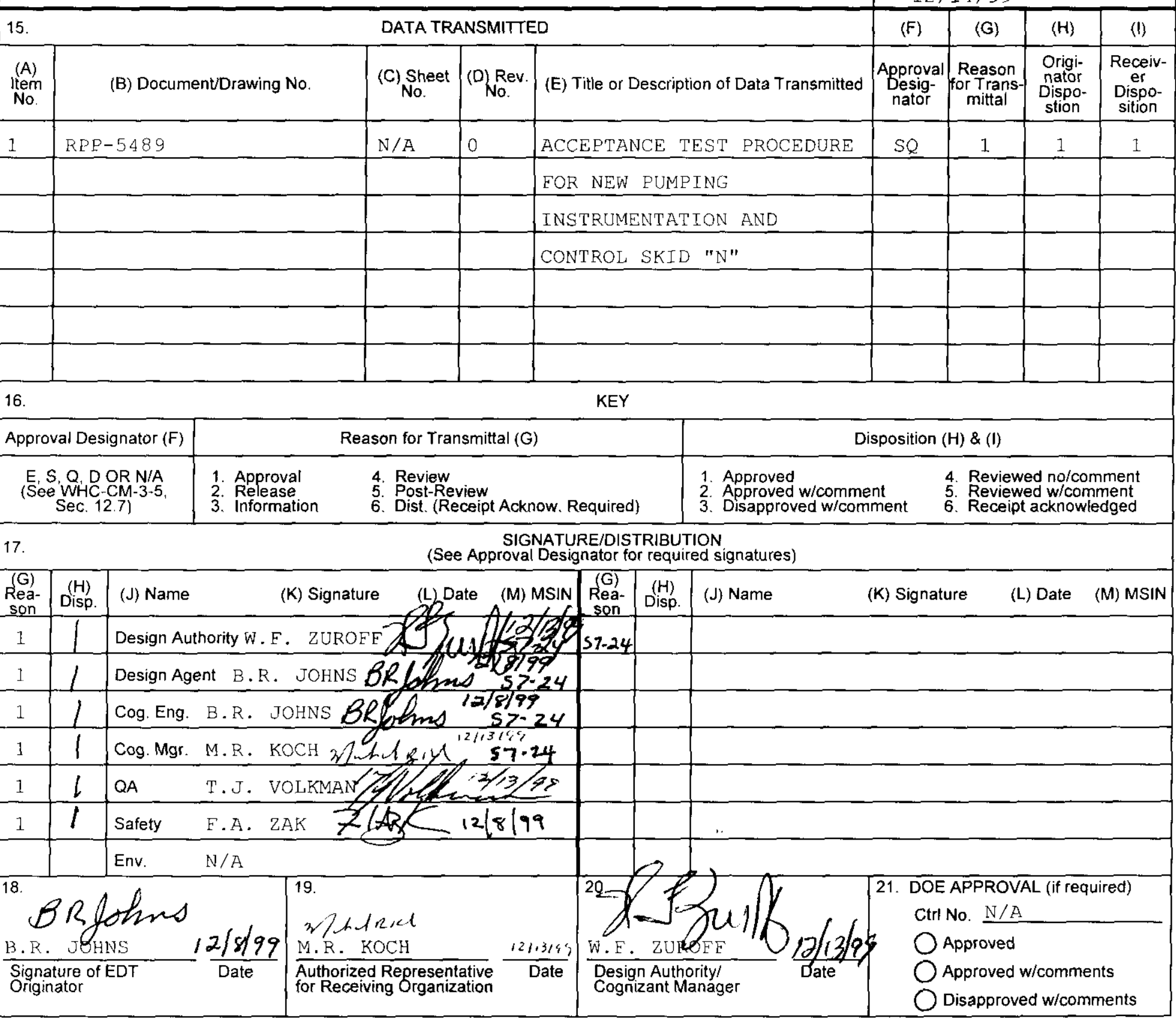




\section{ACCEPTANCE TEST PROCEDURE FOR NEW PUMPING AND INSTRUMENTATION CONTROL SKID "N"}

M. R. $\mathrm{KOCH}$

LOCKHEED MARTIN HANEORD CORPORATION

Richland, WA 99352

U.S. Department of Energy Contract DE-AC06-96RL13200

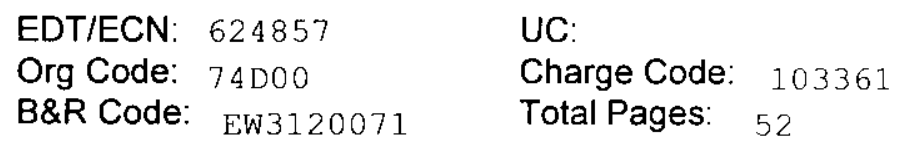

Key Words: PICS, SALT WELL, SKID, INTERIM STABILIZATION, TESTING

Abstract:

This Acceptance Test Procedure (ATP) provides for the inspection and testing of the new Pumping and Instrumentation Control (PIC) skid designed as "N". The ATP will be performed after the construction of the PIC skid in the shop.

TRADEMARK DISCLAIMER. Reference herein to any specific commercial product, process, or service by trade name, trademark, manufacturer, or otherwise, does not necessarily constitute or imply its endorsement, recommendation, or favoring by the United States Government or any agency thereof or its contractors or subcontractors.

Printed in the United States of America. To obtain copies of this document, contact: Document Control Services, P.O. Box 950, Mailstop H6-08, Richland WA 99352, Phone (509) 372-2420; Fax (509) 376-4989.

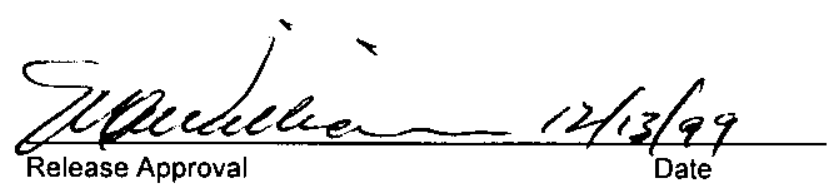

Release Approval

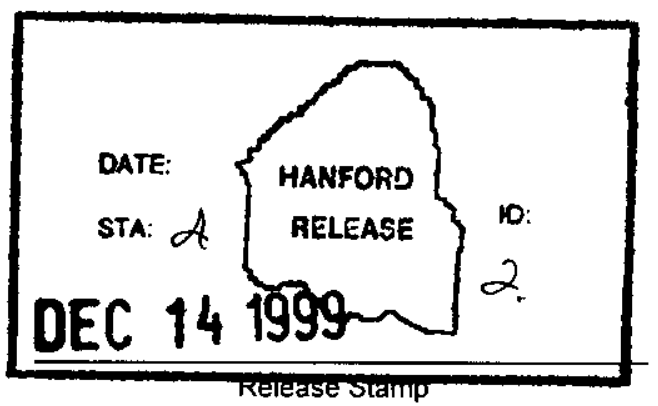




\section{TABLE OF CONTENTS}

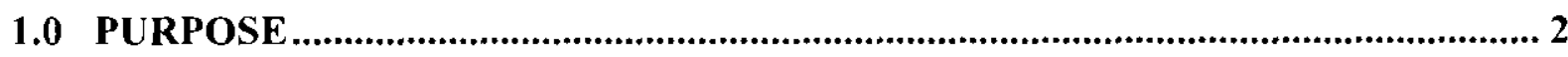

2.0 INFORMATION

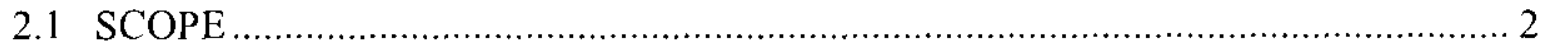

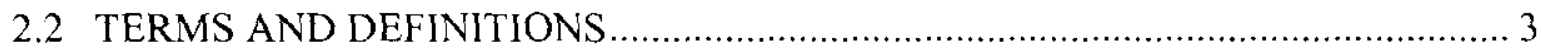

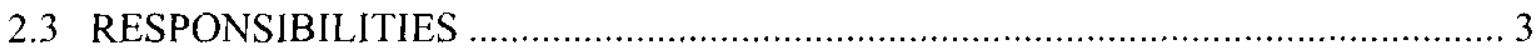

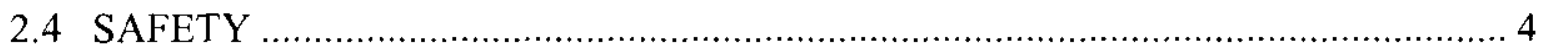

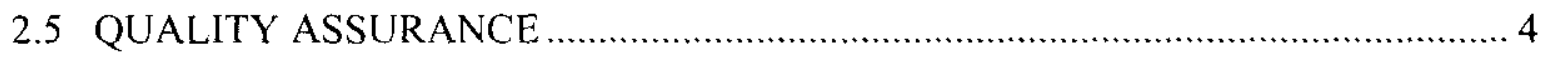

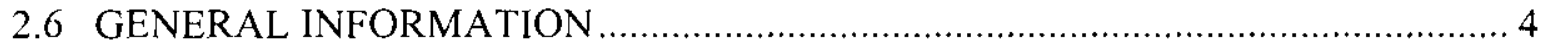

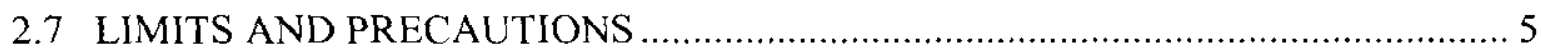

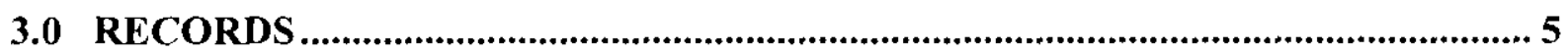

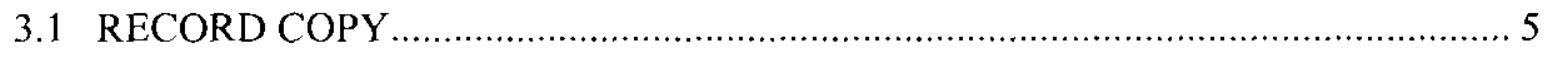

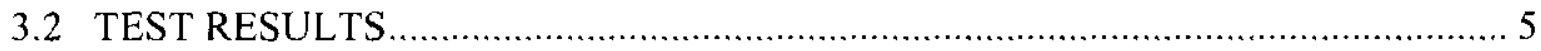

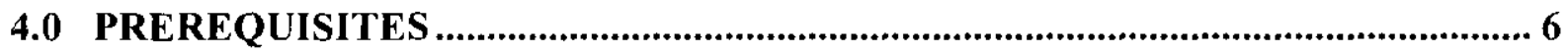

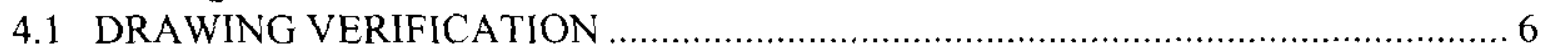

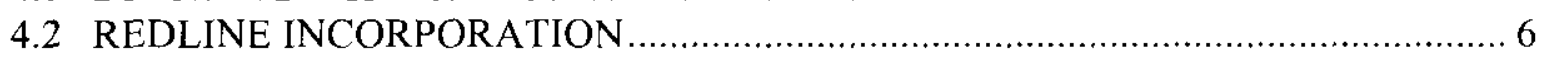

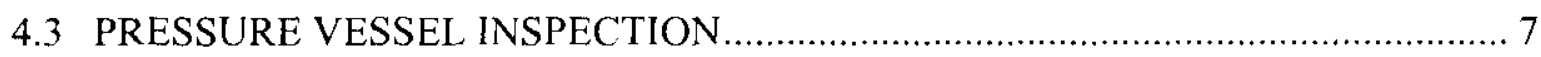

4.4 NATIONAL ELECTRICAL CODE (NEC) INSPECTION ………......................... 7

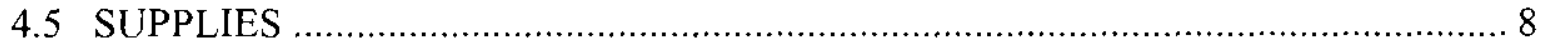

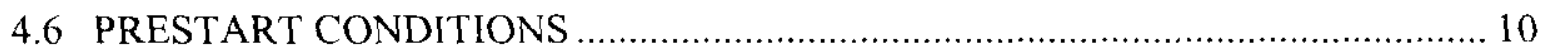

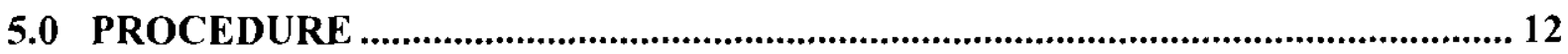

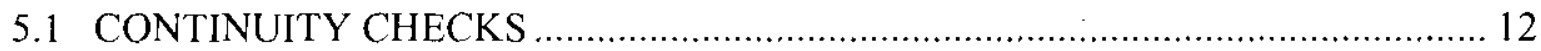

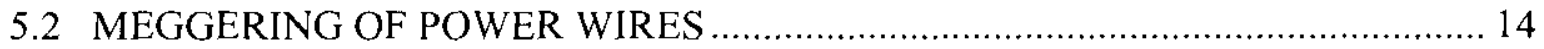

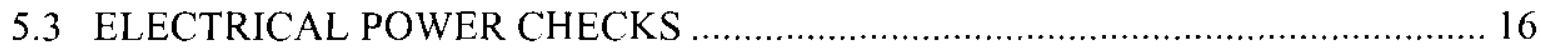

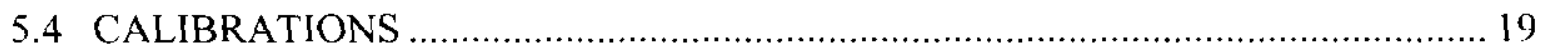

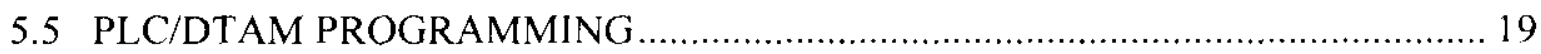

5.6 SKID ELECTRICAL AND PROCESS AIR POWER-UP ………….................... 20

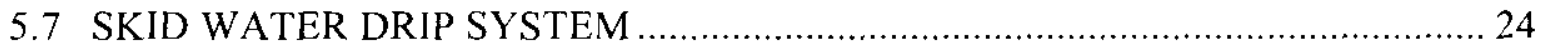

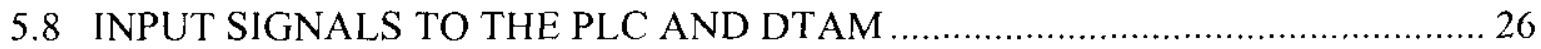

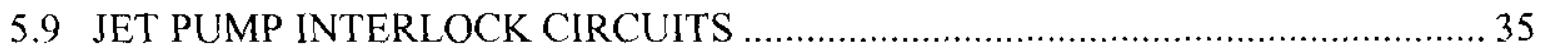

5.10 HEATERS, AIR CONDITIONER AND LIGHTS ……….............................. 44 
RPP-5489

REVISION 0

\section{ACCEPTANCE TEST PROCEDURE FOR NEW PUMPING INSTRUMENTATION AND CONTROL SKID "N"}

\subsection{PURPOSE}

This Acceptance Test Procedure (ATP) verifies proper construction per the design drawings and tests for proper functioning of the Pumping Instrumentation and Control (PIC) skid "N". The scope section lists the systems and functions to be checked. This ATP will be performed at the Site Fabrication Services (SFS) shop upon completion of the construction of the PIC skid.

\subsection{INFORMATION}

\section{$2.1 \quad$ SCOPE}

This Acceptance Test Procedure verifies and/or tests the following items or systems:

2.1.1 Drawing verification (Prerequisites)

2.1.2 Red-line incorporation

2.1.3 Code Inspections (Prerequisites)

2.1.4 Instrument calibrations

2.1.5 Continuity, megger and voltage checks

2.1.6 Programmable Logic Controller (PLC) and Data Table Access Module (DTAM) programming

2.1.7 Air system

2.1.8 Water system

2.1.9 PLC inputs and outputs

2.1.10 Alarms and interlocks

2.1.11 Heaters, air conditioner and lights 
RPP-5489

REVISION 0

\subsection{TERMS AND DEFINITIONS}

2.2.1 DOV - Diaphragm Operated Valve

2.2.2 GPM - Gallons Per Minute

2.2.3 lA - Instrument Air

2.2.4 LDE - Leak Detector Element

2.2.5 PRV - Pressure Relicf Valve

2.2.6 SGT - Specific Gravity Transmitter

2.2.7 WFT - Weight Factor Transmitter

2.2.8 LT - Level Transmitter

2.2.9 WFIE - Weight Factor Instrument Enclosure

2.2.10 PLC - Programmable Logic Controller

2.2.11 DTAM - Data Table Access Module

2.2.12 PSPT - Pump Suction Pressure Transducer

2.2.13 PDPT - Pump Discharge Pressure Transducer

2.2.14 PXPT - Pump Transfer Pressure Transducer

2.2.15 JFPT - Jumper Flush Pressure Transducer

2.2.16 RFPT - Recirculation Flush Pressure Transducer

2.2.17 PIC - Person In Charge

\subsection{RESPONSIBILITIES}

2.3.1 LMHC Quality Assurance is responsible for:

2.3.1.1 Witnessing and signing steps as identified in the Acceptance Test Procedure.

2.3.1.2 Verifying that the ATP sections were performed correctly.

2.3.2 Engineering personnel are responsible for:

2.3.2.1 Identifying the equipment required for the ATP.

2.3.2.2 Recording equipment status and data per this ATP.

2.3.2.3 Conducting pre-job system walk-down.

2.3.2.4 Recording data, exceptions and other notes during the ATP performance.

2.3.2.5 Providing technical support during the ATP.

2.3.2.6 Providing PLC/DTAM programming support during the ATP.

2.3.2.7 Acting as Test Director during the ATP. 


\subsection{SAFETY}

Warning: 120vac energized circuits and leads will be encountered during testing when accessing PLC input/output terminals. Observe appropriate electrical precautions as directed by HNF-PRO-088, Electrical Work Safety.

Warning: Cabinets on the PIC skid contain circuits energized with $480 \mathrm{vac}$ and $120 \mathrm{vac}$. Comply with HNF-PRO-088, Electrical Work Safety.

\subsection{QUALITY ASSURANCE}

LMHC Quality Assurance Inspector is to ensure that testing is performed per this ATP document. The Quality Assurance Inspector shall sign and date each ATP section verifying the data obtained and that the section was performed correctly.

\subsection{GENERAL INFORMATION}

2.6.1 All data entries recorded in this procedure shall be made in black or blue ink.

2.6.2 Editorial changes required to this ATP shall be made by redlining the affected section by the engineer as long as the changes do not impact the personnel safety or the technical aspects of this ATP. These changes shall be recorded on the ATP log sheet.

2.6.3 Unexpected results during testing shall be logged in the Acceptance Test Procedure "Exception Log" and documented on an Acceptance Test Procedure "Exception Record."

2.6.4 Technical changes to this ATP shall be logged as "Exceptions and documented on the "Exception Record."

2.6.5 Do not perform any part of this ATP on faulty equipment. If faulty equipment is discovered, STOP the execution of that section of the ATP and resolve the problem OR continue with another section until the problem is repaired.

2.6.6 If the performance of the ATP is suspended for any reason, ensure the equipment is left in a safe condition per the direction of the test engineer and/or PIC and any Lock and Tag system requirements are met before leaving the test site.

2.6.7 This ATP DOES NOT contain separate data/verification sheets. Verification of the ATP steps and validity of data is recorded in this ATP next to each step as required.

2.6.8 A Job Hazard Analysis for shall be used in conjunction with the Pre-job safety meeting form when any unusual hazards are identified. The Pre-job meeting form (attached to this ATP) shall be used to document all attendees. NOTE: No unusual hazards are expected during the performance of this ATP.

2.6.9 An ATP log shall be used to record comments concerning the ATP performance such as each day's testing activities. 


\section{RPP-5489 \\ REVISION 0}

2.6.10 The engineer or PIC may deviate from test steps if necessary to ensure safe equipment configuration during testing or suspension of testing.

Configuration shall be noted so the equipment may be restored at the resumption of testing.

2.6.11 Alarms may be acknowledged during testing at the direction of the test engineer or PIC if specific instructions are not given in the test steps.

2.6.12 Sections 4.2, 4.3,4.4, and 5.4 can be performed out of sequence in order to facilitate the completion of this ATP.

2.6.13 Sections 5.8 through 5.10 can be performed out of order as directed by the test engineer and/or PIC as necessary to facilitate ATP performance.

2.6.14 All personnel initialing and/or signing this ATP shall enter their signature and initials on the Procedure Performer Signature Sheet on the last page of this document.

\subsection{LIMITS AND PRECAUTIONS}

NONE

\subsection{RECORDS}

\subsection{RECORD COPY}

The record copy of this ATP when completed shall be kept with the fabrication work package.

\subsection{TEST RESULTS}

A test report, RPP-5490 shall be issued with the final test results upon completion of this ATP. 


\subsection{PREREQUISITES}

\subsection{DRAWING VERIFICATION}

A check of the constructed skid is to be compared to either the redlined drawings or the final unreleased skid drawings. Engineering and Quality Assurance shall verify the accuracy of the essential and support drawings. Engineering shall determine a resolution for all discrepancies by either correcting the drawings or changing the equipment.

The following drawings shall be walked down for verification of proper construction of the skid:

4.1.1 Wire terminations and wiring labels on drawings $\mathrm{H}-14-103784$, sheets 7 through 12 and $\mathrm{H}-14-103787$, sheet 5.

4.1.2 Panel board arrangement on drawing H-14-103790.

4.1.3 Flow diagrams on drawings H-14-103784, sheet 5 and H-14-103789.

Drawing verification completed. (Final drawing release is not required to continue with this ATP.)

Engineer Signature Date

Quality Assurance Inspector Signature Date

\subsection{REDLINE INCORPORATION}

4.2.1 Ensure the relines identified on the construction drawings in the fabrication work package are incorporated on the final drawings for skid " $N$ " prior to the drawings being released. NOTE: Redlines must meet the intent of the markups and may not be exactly the same in order to meet drafting standards or for clarity.

4.2.2 Engineer to verify the redline incorporation is completed by signing below.

Engineer Signature Date

Quality Assurance Inspector Signature Date




\subsection{PRESSURE VESSEL INSPECTION}

A pressure vessel inspection by a third party inspector is required for the air compressor receiver tank and relief valves located in the air compressor cabinet and the water tank and relief valves located in the water cabinet. The inspection is to verify that the equipment meets National Codes for pressure vessels. An outside-certifies inspector shall perform this inspection. (This inspection shall be completed prior to testing the air compressor and water systems.)

Pressure vessel inspection report received. (The ATP can continue before the report is received, but must be received prior to performing section 5.6.)

Report \#'s:

Quality Assurance Inspector Signature

Date

Information has been supplied to the PMS database to add relief valve inspection for the air compressor and water tanks. Completion of the database update will be tracked by the Acceptance for Beneficial Use documentation.

Engineer Signature

Date

\subsection{NATIONAL ELECTRICAL CODE (NEC) INSPECTION}

4.3.1 An NEC inspection shall be performed to verify compliance to NFPA 70, latest version.

4.3.2 Areas in particular to be inspected are the $480 \mathrm{vac}$ and $120 \mathrm{vac}$ wiring and grounding.

4.3.3 An NEC inspection sticker is to be placed on the inside or the outside of the panel board door upon the NEC inspector's acceptance of the electrical portion of the skid.

The NEC inspection sticker is placed on the panel board door and the NEC report received. (This needs to be completed prior to the section 5.0 functional checks.) Report \# 


\subsection{SUPPLIES}

The following supplies are required for this ATP. NOTE: Test sections may commence prior to assembly of all the test equipment. Engineer and/or PIC are to ensure test equipment is available prior to the start of each section.

\subsubsection{Volt/ohm meter (VOM): Portable, 0-600vac}

Calibration No. Exp. Date QA

Calibration No. Exp. Date QA

Calibration No. Exp. Date QA

\subsubsection{Transmation current (milliamp) simulator or equivalent}

Calibration No. Exp. Date QA

Calibration No. Exp. Date QA

Calibration No. Exp. Date QA

Calibration No. Exp. Date QA

Calibration No. Exp. Date QA

4.4.3 Manometer capable of a minimum of 5 inches water gauge to a maximum of 125 inches water gauge for this ATP and a read-out of variable test pressure.

Calibration No. Exp. Date QA

Calibration No. Exp. Date QA

Calibration No. Exp. Date QA

\subsubsection{Megaohm meter, at least 500vac range.}

Calibration No. Exp. Datc QA

4.4.5_ 480vac, 3 phase, 30-ampere power supply for PIC skid.

4.4 .6

4.4 .7

4.4 .8

4.4 .9 Selector switches ( 3 each) with at least one NO and one NC contact. Proximity switches (for simulating LS-1 and LS-2), 2 each. Leak detector probes ( 2 each) not required to be green tagged. Heat gun to warm thermocouple probes. 


\section{RPP-5489 \\ REVISION 0}

4.4.10 A thermocouple simulator for testing the thermocouples for the pump and jumper..

4.4.11_Buckets or pans for water for leak detector test and catching water from DIP tubes and relief valves.

4.4.12 _._. Water supply and hose to fill water tank. 


\subsection{PRESTART CONDITIONS}

4.5.1_ Fill the water tank at least one-third to half full of water. Operate the appropriate valves in the water cabinet to accomplish this task.

4.5.2___ Ensure the PIC skid is grounded in preparation for ATP testing.

4.5.3 Ensure the following PIC skid valves in the WFIE cabinet are OPEN prior to starting this ATP.

SALW-V-6035N (EQUALIZING) SALW-V-6036N (EQUALIZING)

4.5.4 Ensure the following PIC skid valves are CLOSED prior to starting this ATP.

Air Compressor Cabinet

SALW-V-6025N

SALW-V-6026N

SALW-V-6034N

SALW-V-6043N

SALW-V-6044N

SALW-V-6046N

SALW-V-6047N

SALW-V-6048N

SALW-V-6049N

SALW-V-6050N

SALW-V-6051N

SALW-V-6053N

WFIE Cabinet

SALW-V-6001N

SALW-V-6002N

SALW-V-6003N

SALW-V-6004N

SALW-V-6005N

SALW-V-6006N

SALW-V-6007N

SALW-V-6008N

SALW-V-6011N

SALW-V-6012N

SALW-V-6013N

SALW-V-6014N
Water Cabinet

SALW-V-6027N

SALW-V-6028N

SALW-V-6029N

SALW-V-6030N

SALW-V-6031N

SALW-V-6032N

SALW-V-6037N

SALW-V-6052N
SALW-V-6015N

SALW-V-6016N

SALW-V-6017N

SALW-V-6018N

SALW-V-6019N

SALW-V-6020N

SALW-V-6021N

SALW-V-6035N(LOW)

SALW-V-6035N(HIGH)

SALW-V-6036N(LOW)

SALW-V-6036N(HIGH) 
REVISION 0

4.5.5 Ensure the following PIC skid circuit disconnects, breakers and fuses are OPEN or OFF prior to starting this ATP.

SALW-DS-6002N

SALW-DS-6004N
SALW-DS-6003N

SALW-DS-6005N

(The following breakers are located in distribution panel SALW-DP$6001 \mathrm{~N}$.

Breaker "MAIN"
Breaker 1
Breaker 3
Breaker 5
Breaker 7
Breaker 9
Breaker 11
Breaker 13

Breaker 2

Breaker 4

Breaker 6

Breaker 8

Breaker 10

Breaker 12

Breaker 14

(The following fuses are located in the Instrument Enclosure.)

$\begin{array}{rrr}F A & F B & F C \\ F D & \text { LD }\end{array}$

4.5.6 Check for loose electrical connections at the following locations:

Terminal boards in the Instrument Enclosure.

Motor starters and disconnect switches.

Terminal board in junction box inside the WFIE cabinet.

Terminal board in heat trace splice box outside WFIE cabinet.

Terminal board in junction box for FGM outside WFIE cabinet.

Distribution panel board.

4.5.7_ Ensure desiccant and filters are installed in the air compressor dryer and filters prior to performing sections 5.6 and 5.7.

4.5.8_A A pre-job safety meeting shall be held prior to performing section 5.0. 
RPP-5489

REVISION 0

\subsection{PROCEDURE}

\subsection{CONTINUITY CHECKS}

Continuity checks shall be performed with a calibrated VOM. Perform the checks as identified below. Readings are to be less than $1 \mathrm{ohm}$. Record ohm readings on the line(s) provided. Out of tolerance readings must be corrected and rechecked prior to going to the next section. NOTE: NEC inspection must be completed prior to proceeding with this section.

5.1.1 480vac main power plug to the line side of the main disconnect switch (SALW-DS-6002N). Check all three phases and ground.

(RED) $\_$(YELLOW) _ (BLUE) __ (GND)

5.1.2 Load side of main disconnect switch (SALW-DS-6002N) to the line side of transformer disconnect switch (SALW-DS-6003N). Check the two phases used and ground.

(RED)

(YELLOW OR BLUE)

(GND)

5.1.3 Load side of main disconnect switch (SALW-DS-6002N) to the line side of the jet pump motor starter (SALW-DS-6005N). Check all three phases and ground.

(RED) __ (YELLOW) (BLUE) __ (GND)

5.1.4 Load side of main disconnect switch (SALW-DS-6002N) to the line side of the air compressor motor starter (SALW-DS-6004N). Check all three phases and ground.

(RED) (YELLOW)

(BLUE) (GND)

5.1.5 Load side of the transformer disconnect switch (SALW-DS-6003N) through the primary of the transformer (SALW-XFMR-6001N). Check between the two phase wires going to the transformer.

Continuity through the transformer primary. 
5.1.6 Line side of the main breaker in panel board (SALW-DP-6001N) through the secondary of transformer (SALW-XFMR-6001N). Check between the two phases and between each phase and neutral going to the transformer secondary.

Phase A to phase $\mathrm{C}$, continuity through transformer secondary.

Phase A to neutral, continuity through transformer secondary.

Phase $\mathrm{C}$ to neutral, continuity through transformer secondary.

5.1.7 Load side of breakers in distribution panel (SALW-DP-6001N) to terminal point identified.

Circuit 3 to TB10 in Instrument Enclosure (CKT3-H, CKT3-N)

Circuit 5 to TB13 in Instrument Enclosure (CKT5H, CKT5N)

Circuit 12 to Air Conditioner/Heater receptacle in Instrument Enclosure

Circuit 6 to safe side terminal block in Intrinsic Safe panel

Circuit 1 to terminal block in FGM power junction box

Circuit 11 to terminal block in FGM power junction box

Circuit 13 to terminal block in FGM power junction box

Circuit 14 to terminal block in FGM power junction box

Circuit 2 to terminal block in FGM heat trace splice box

Circuit 10 to terminal block in FGM heat trace splice box

Circuit 4 to receptacle in air compressor cabinet

Circuit 7 to receptacles in WFIE cabinet

Circuit 8 to receptacle in water cabinet

Circuit 9 to outside receptacle below panel board

5.1.8 Section 5.1 completed and all recorded readings within tolerance.

Quality Assurance Inspector Signature

Date 


\subsection{MEGGERING OF POWER WIRES}

The power wires shall be checked for resistance to ground and phase to phase. A 500-volt megger shall be used for this check. Minimum acceptable readings are greater than 1000 megaohm or infinity. Test the circuits listed below. Record readings on the lines provided. Out of tolerance readings must be corrected and rechecked prior to going to the next section.

5.2.1 Each of the three phases at the pins of the power plug to ground and phase to phase. (Ensure main disconnect SALW-DS-6002N is OPEN.)
A-GND
; B-GND
; C-GND
; A-B
; A-C
B-C

5.2.2 Each of the three phases at the load side of the main disconnect switch (SALW-DS-6002N) to ground and phase to phase. (Ensure switches SALWDS-6003N, SALW-DS-6004N and SALW-DS-6005N are OPEN.)
A-GND ; B-GND
; C-GND ; A-B ; A-C $\mathrm{B}-\mathrm{C}$

5.2.3 Each of the two phases on the load side of the transformer disconnect switch (SALW-DS-6003N) to ground.
A-GND ; B-GND

5.2.4 Each of the three phases on the load side of the air compressor motor to ground.

A-GND ; B-GND ; C-GND Disconnect the neutral at the distribution panel from ground.

5.2.6 Each of the two phases and neutral to ground at the distribution panel.

A-GND ; B-GND ; NEUTRAL-GND Reconnect the neutral back to ground at the distribution panel.

5.2.8_Disconnect the circuit 6 wire at the safe side terminal block in the Intrinsic Safe panel.

5.2 .9 Ensure all the heaters, lights and air conditioner are disconnected or unplugged from the $120 \mathrm{vac}$ circuits. 


\section{RPP-5489}

\section{REVISION 0}

5.2.10 Megger each of the 14 circuits from the load side of the breaker or from the wire disconnected at the load side of the breaker to ground in the distribution panel.

NOTE: Disconnect each wire from the load side of the breaker on all the ground fault breakers prior to performing the megger check. This will prevent damage to the ground fault circuitry in the breaker. Reconnect the wire after meggering.

CKT \#1 to GND

CKT \#3 to GND

CKT \#5 to GND

CKT \#7 to GND

CKT \#9 to GND

CKT \#11 to GND

CKT \#13 to GND
CKT \#2 to GND

CKT \#4 to GND

CKT \#6 to GND

CKT \#8 to GND

CKT \#10 to GND

CKT \#12 to GND

CKT \#14 to GND

5.2.11_Ensure the load-side wire at each breaker where disconnected is reconnected.

5.2.12 Reconnect the circuit 6 wire to the safe side terminal block in the Intrinsic safe panel.

5.2.13 Reconnect any wires disconnected in step 5.2.9 above. (Unplugged items do not have to be plugged back in.)

5.2.14 Section 5.2 completed and all recorded readings are within tolerance.

Quality Assurance Inspector Signature

Date 
RPP-5489

REVISION 0

\subsection{ELECTRICAL POWER CHECKS}

The voltage checks are to verify proper voltages throughout the skid at specific termination points. Voltages checked are $480 \mathrm{vac}, 3$ phase; 120vac, single phase; $24 \mathrm{vdc}$; and $32 \mathrm{vdc}$. Out of tolerance readings must be corrected when found before going to the next step in this section.

5.3.1_Ensure that all electrical connections are completed. Wires lifted during meggering checks are to be reconnected.

5.3.2_Ensure all switches and breakers are open and the six fuses in the Instrument Enclosure are open.

5.3.3 Ensure all the fuses are installed in the two safety switches (SALW-DS$6002 \mathrm{~N}$ and SALW-DS-6003N) and motor starters (SALW-DS-6004N and SALW-DS-6005N) including the control transformer fuses.

5.3.4 Connect the main power plug on the skid to a three phase, $480 \mathrm{vac}$ power source. Source is to be protected by no greater than a 30 ampere over current protection device.

5.3.5_ Turn ON the power source to the skid.

5.3.6 Ensure 480vac $+/-20 \mathrm{vac}$ on the line side of the main disconnect switch (SALW-DS-6002N). Record the voltage readings. vac, A-B A-C B-C Close the main disconnect switch (SALW-DS-6002N).

5.3.8_Ensure $480 \mathrm{vac}+/ 20 \mathrm{vac}$ on the line side of the transformer disconnect switch (SALW-DS-6003N). Record the voltage readings.

vac

5.3.9 Ensure 480vac $+/-20 \mathrm{vac}$ on the line side of the air compressor motor starter (SALW-DS-6004N). Record the voltage readings. vac, A-B vac, A-C B-C

$5.3 .10 \_$Ensure $480 \mathrm{vac}+/-20 \mathrm{vac}$ on the line side of the pump motor starter (SALW-DS-6005N). Record the voltage readings.

vac, A-B

vac, A-C

B-C 
RPP-5489

REVISION 0

5.3.11___ Remove the dead front on the panel board (SALW-DP-6001N) for access to the main breaker for a voltage measurement.

5.3.12_Close the transformer disconnect switch (SALW-DS-6003N).

5.3.13 Check for $240 \mathrm{vac}+/ 20 \mathrm{vac}$ on the line side of the main breaker. Record the voltage reading.

$\mathrm{vac}$

5.3.14_Open the transformer disconnect switch (SALW-DS-6003N).

5.3.15_Replace the dead front on the panel board (SALW-DP-6001N).

5.3.16_Close the transformer disconnect switch (SALW-DS-6003N).

5.3.17_Close the 100 ampere main breaker in the panel board (SALW-DP$\overline{6001 N})$.

5.3.18 Ch_ Check the voltages for the circuits at the locations designated. Record the voltages in the space provided.

\begin{tabular}{|c|l|c|c|c|}
\hline CKT \# & \multicolumn{1}{|c|}{ Check voltage at } & $\begin{array}{c}\text { Bkr Open voltage } \\
(\text { appr. 0vac })\end{array}$ & $\begin{array}{c}\text { Bkr Closed voltage } \\
(120+/-10 \mathrm{vac})\end{array}$ & $\begin{array}{c}\text { Open } \\
\mathrm{Bkr}\end{array}$ \\
\hline 1 & FGM JUNCTION BOX & & & \\
\hline 2 & FGM HT BOX & & & \\
\hline 3 & TB10, INSTR ENCL & & & \\
\hline 4 & RCPT, AIR COMPR & & & \\
\hline 5 & TB13, INSTR ENCL & & & \\
\hline 6 & TB, INTRINSIC PNL & & & \\
\hline 7 & RCPT, WFIE CAB. & & & \\
\hline 8 & RCPT, WATER CAB. & & & \\
\hline 9 & OUTSIDE RCPT & & & \\
\hline 10 & FGM HT BOX & & & \\
\hline 11 & FGM JUNCTION BOX & & & \\
\hline 12 & RCPT, INSTR ENCL & & & \\
\hline 13 & FGM JUNCTION BOX & & & \\
\hline 14 & FGM JUNCTION BOX & & & \\
\hline
\end{tabular}


RPP-5489

REVISION 0

5.3.19_Ensure fuses FA, FB, FC, FD, LD, and HT are installed in the fuseholders in the Instrument Enclosure.

5.3.20_Close breakers 3 and 5 in the distribution panel (SALW-DP-6001N).

5.3.21 Ensure $120 \mathrm{vac}+/-10 \mathrm{vac}$ on the line side at the following fuseholder load side points.

FA vac; $\mathrm{FB}$ vac; $\mathrm{FC}$ vac;

FD vac;

LD vac; HT vac.

5.3.22___Ensure $24 \mathrm{vdc}+/-2 \mathrm{vdc}$ at each $24 \mathrm{volt}$ power supply.

First power supply ___ _ _ S _ Second power supply

5.3.23_Close breaker 6 in the distribution panel (SALW-DP-6001N).

5.3.24_Ensure $32 \mathrm{vdc}+0 /-4 \mathrm{vdc}$ at the output of the 3991 power supply in the Intrinsic safe panel (terminals 3 and 4). NOTE: Low voltage reading may indicate the $240 / 120 \mathrm{vac}$ input power switch on the side of the 3991 supply is in the wrong position.)

5.3.25_Open breakers 3, 5 and 6 in the panel board (SALW-DP-6001N).

5.3.26___ Open the 100 ampere main breaker in the panel board (SALW-DP$6001 \mathrm{~N})$.

5.3.27_Open the transformer disconnect switch (SALW-DS-6003N).

5.3.28_Open the main disconnect switch (SALW-DS-6002N).

5.3.29 Voltage checks completed and readings within tolerance.

Quality Assurance Inspector Signature

Date 


\subsection{CALIBRATIONS}

Instrumentation equipment on the skid requires calibration prior to the functional testing. Engineering will verify the calibration completion by checking for current calibration stickers on the equipment and checking off the completed calibrations in the table below.

\begin{tabular}{|l|l|l|}
\hline \multicolumn{1}{|c|}{ INSTRUMENT } & \multicolumn{1}{|c|}{ LOCATION } & CAL. STICKER ON \\
\hline SALW-PS-6004N & AIR COMPR. CABINET & \\
\hline SALW-WFT-6002N & WFIE CABINET & \\
\hline SALW-LT-6003N & WATER CABINET & \\
\hline SALW-SGT-6001N & WFIE CABINET & \\
\hline SALW-CONV-6001N & WFIE CABINET & \\
\hline SALW-FQIT-6001N & INSTRUMENT ENCL. & \\
\hline SALW-PI-6006N & AIR COMPR. CABINET & \\
\hline SALW-PI-6007N & AIR COMPR. CABINET & \\
\hline SALW-PI-6008N & WATER CABINET & \\
\hline SALW-PI-6001N & WFIE CABINET & \\
\hline SALW-PI-6002N & WFIE CABINET & \\
\hline SALW-PI-6003N & WFIE CABINET & \\
\hline SALW-PI-6004N & WFIE CABINET & \\
\hline SALW-PI-6005N & WFIE CABINET & \\
\hline SALW-PI-6011N & INSTRUMENT ENCL. & \\
\hline SALW-PI-6012N & INSTRUMENT ENCL. & \\
\hline
\end{tabular}

Calibrations completed. Work package nos.

\subsection{PLC/DTAM PROGRAMMING}

This section is where the programs for the PLC and DTAM will be entered into the equipment. Power will be required (circuit 5) at the Instrument enclosure to power up the PLC and DTAM and for the GFCI receptacle. Engineering will program the equipment from a laptop computer. Final software programs shall be documented as required by HNF- 5034 . This documentation is not part of this ATP, but will be documented after the OTP in document RPP-5492.

PLC/DTAM programmed. 


\subsection{SKID ELECTRICAL AND PROCESS AIR POWER-UP}

NOTE: The pressure vessel inspection report must be received prior to proceeding with this section. Refer to section 4.3. Ensure desiccant is in the air dryer and the filters installed.

5.6.1 Ensure the skid is connected to the $480 \mathrm{vac}$ power source and grounded before proceeding with this functional test.

5.6.2_Energize or ensure energized the PIC skid by CLOSING the following disconnect switches in the order listed below.

SALW-DS-6002N

SALW-DS-6003N

SALW-DS-6004N

SALW-DS-6005N

5.6.3 Energize or ensure energized the breakers in the panel board (SALW-

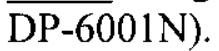

\begin{tabular}{l} 
Breaker "MAIN" \\
\hline Breaker 1 \\
Breaker 3 \\
Breaker 5 \\
Breaker 7 \\
Breaker 9 \\
\hline Breaker 11 \\
\hline Breaker 13
\end{tabular}

Breaker 2
Breaker 4
Breaker 6
Breaker 8
Breaker 10
Breaker 12
Breaker 14

5.6 .4 ACKNOWLEDGE any initial skid alarms.

5.6.5 OPEN valves SALW-V-6034N, SALW-V-6050N, and SALW-V$\overline{6053 \mathrm{~N}}$ in the Air compressor cabinet.

5.6.6 START the air compressor by positioning the positioning the switch on SALW-DS-6004N to the ON position.

5.6.7 Ensure the air compressor starts and builds up pressure and shuts off at 86 to 94 psig as indicated by pressure gauge SALW-PI-6006N. RECORD the shut off pressure: psig.

5.6.8_ CHECK the tubing in the air compressor cabinet using a soap and water test to visually identify any air leaks. Repair as necessary. Deenergize the compressor motor and bleed off air as necessary to make repairs. 
RPP-5489

REVISION 0

5.6 .9

BLEED off air by slowly opening valve SALW-V-6043N until the compressor restarts and note the restart pressure as read on gauge SALW-PI$6006 \mathrm{~N}$. CLOSE valve SALW-V-6043N when the compressor restarts. RECORD the restart pressure reading: psig.

5.6 .10 ENSURE the compressor restarts between 58 to 62 psig.

5.6.11 Valve in air to the PIC skid water tank by performing the following steps.

5.6.12 Check for air leaks as each of the remaining steps in this section are performed.

5.6.13_ SLOWLY OPEN valve SALW-V-6025N located in the air compressor cabinet.

5.6.14___ SLOWLY OPEN valve SALW-V-6027N located near the water tank.

5.6.15_SLOWLY OPEN valve SALW-V-6052N located near the water tank

5.6.16___ ADJUST pressure regulator valve SALW-PCV-6006N to $30 \mathrm{psi}(+/-$ $3 \mathrm{psi}$ ) as indicated by pressure gauge SALW-PI-6008N on the outside of the water cabinet.

5.6.17___ ACTUATE the lever on relief valve SALW-PRV-6004N on the top of the air compressor tank and hold open approximately 5 seconds. (Air system is to be at full pressure of approximately $90 \mathrm{psi}$.)

5.6.18___ENSURE the relief valve SALW-PRV-6004N seats properly when the lever is released.

5.6.19___ ACTUATE the lever on relief valve SALW-PRV-6005N on the top of the water tank and hold open approximately 5 seconds. (Water system air pressure is to be at full pressure of approximately 30psi.)

5.6.20__ ENSURE the relief valve SALW-PRV-6005N seats properly when the lever is released.

5.6.21 VALVE IN air to the WFIE cabinet by performing the following steps.

5.6.22__ SLOWLY OPEN valves SALW-V-6051N located inside the air compressor cabinet and SALW-V-6026N located on the outside of the air compressor cabinet.

5.6.23 SLOWLY OPEN valve SALW-V-6001N located in the WFIE cabinet. (NOTE: SALW-PRV-6002N may open if pressure through SALW-PCV$6001 \mathrm{~N}$ is too high.) 
5.6.24_ADJUST pressure control valve SALW-PCV-6001N in the WFIE cabinet to $20 \mathrm{psi}(+/-2.5 \mathrm{psi})$ as indicated by the pressure gauge located on the face of the valve.

5.6.25_SLOWLY OPEN valve SALW-V-6004N located in the WFIE cabinet.

5.6.26_SLOWLY OPEN valve SALW-V-6003N located in the WFIE cabinet.

5.6.27_ SLOWLY OPEN valve SALW-V-6005N located in the WFIE cabinet.

5.6.28_ SLOWLY OPEN valve SALW-V-6006N located in the WFIE cabinet.

5.6.29_ SLOWLY OPEN valve SALW-V-6007N located in the WFIE cabinet.

5.6.30_ SLOWLY OPEN valve SALW-V-6020N located in the WFIE cabinet.

5.6.31_ SLOWLY OPEN valve SALW-V-6021N located in the WFIE cabinet.

5.6.32_ SLOWLY OPEN valve SALW-V-6019N located in the WFIE cabinet.

5.6.33 ADJUST the air flow through the diptubes by performing the following steps.

5.6.34_ADJUST flow to dip tube to $1.5 \mathrm{CFH}(+/-0.5 \mathrm{CFH})$ as indicated by SALW-FIV-6002N.

5.6.35_ADJUST flow to dip tube to $1.5 \mathrm{CFH}(+/-0.5 \mathrm{CFH})$ as indicated by SALW-FIV-6003N.

5.6.36_ADJUST flow to dip tube to $1.5 \mathrm{CFH}(+/-0.5 \mathrm{CFH})$ as indicated by SALW-FIV-6004N.

5.6.37_ENSURE air flow from pressure regulator SALW-PCV-6007N by slowly opening valve SALW-V-6044N in the air compressor cabinet and then reclose the valve.

5.6.38___ ENSURE air flow from pressure regulator SALW-PCV-6008N by slowly opening valve SALW-V-6048N in the air compressor cabinet and then reclose the valve.

5.6.39_ENSURE air flow from the SALW-V-6042N port at the air compressor cabinet by slowly opening valve SALW-V-6046N in the air compressor cabinet and then reclose the valve. 
RPP-5489

REVISION 0

5.6.40 ENSURE air flow from the drain line by slowly opening valves SALW-V$6047 \mathrm{~N}$ and SALW-V-6046Nin the air compressor cabinet and then reclose the two valves.

5.6.41 Engineer to ENSURE section 5.6 is completed and sign below.

Engineer Signature Date

5.6.42 Quality Assurance Inspector to VERIFY that section 5.6 is complete and sign below.

Quality Assurance Inspector Signature

Date 
RPP-5489

REVISION 0

\subsection{SKID WATER DRIP SYSTEM}

5.7.1_ PROVIDE a container to capture water expelled from the dip tubes and the pressure relief valve SALW-PRV-6001N on the outside of the WFIE cabinet.

5.7.2 ACTUATE the Dip Tube Drip system by SLOWLY OPENING the following valves in the WFIE cabinet:

SALW-V-6016N

SALW-V-6013N

SALW-V-6008N

CAUTION: Relief valve SALW-PRV-6001N will actuate and relieve pressure at 25 psig.

\subsubsection{SLOWLY OPEN SALW-V-6018N WHILE CAREFULLY}

ADJUSTING Pressure Regulator SALW-PCV-6005N located in the WFIE cabinet to 20psig (+/-2psig) as indicated on gauge SALW-PI-6001N in the WFIE cabinet.

5.7 .4 ADJUST valve SALW-V-6014N to allow approximately 2 drops/second as indicated by sight glass SALW-FG-6001N.

5.7.5_ADJUST valve SALW-V-6015N to allow approximately 2 drops/second as indicated by sight glass SALW-FG-6002N.

5.7.6 VALVE OUT the dip tube drip system by SLOWLY CLOSING or ENSURING CLOSED the following valves located in the WFIE cabinet.

SALW-V-6015N

SALW-V-6014N

SALW-V-6008N

SALW-V-6013N

SALW-V-6019N

SALW-V-6021N

SALW-V-6020N

SALW-V-6007N

SALW-V-6006N

SALW-V-6005N 


\section{RPP-5489 \\ REVISION 0}

5.7.7 Engineer to ENSURE section 5.7 is completed and sign below.

Engineer Signature Date

5.7.8 Quality Assurance Inspector to VERIFY that section 5.7 is complete and sign below.

Quality Assurance Inspector Signature Date 
RPP-5489

REVISION 0

\section{$5.8 \quad$ INPUT SIGNALS TO THE PLC AND DTAM}

5.8.1 ENSURE the two leak detector probes are connected to the skid at the Instrument Enclosure.

5.8.2 ENSURE a normally closed switch is connected to "FGM" and "CKT5H-A" on terminal board TB4 in the Instrument Enclosure.

5.8.3 ENSURE a normally closed switch is connected to "DIL-F" and "CKT5H-A" on terminal board TB4 in the Instrument Enclosure.

5.8.4 ENSURE a normally closed switch is connected in parallel to the "RECIRC-1" and "RECIRC-2" wires on the Intrinsic safe terminal block in the Intrinsic Safe panel.

5.8.5 ENSURE two proximity switches are connected to the intrinsic safe terminal block in the Intrinsic Safe panel. Connect a normally closed proximity switch temporarily labeled as LS-1 to "LS-1(+) and LS-1(-)" and a normally open proximity switch temporarily labeled as LS-2 to "LS-2(+) and LS-2(-)". ACTUATE the proximity switches by placing metal in front the switch faces.

5.8.6_ENSURE the DIP switches for the Pepperl-Fuch module in the Intrinsic Safe panel are set to the correct positions per H-14-103784, sheet 7 .

\section{WATER TANK LEVEL TRANSMITTER}

5.8.7 ENSURE valve SALW-V-6029N located in the water tank cabinet is CLOSED.

5.8.8 ENSURE valve SALW-V-6031N located in the water cabinet is CLOSED.

5.8.9 CONNECT a test manometer pressure source that can output at least 62" water gauge to the HIGH PRESSURE vent/test port of level transmitter SALW-LT-6003N.

5.8.10_ENSURE the LOW PRESSURE vent/test port of level transmitter SALW-LT-6003N is OPEN to atmosphere.

5.8.11_ADJUST the test manometer connected to SALW-LT-6003N to a pressure of 31 " water gauge (+/-1"). Record reading 
RPP-5489

REVISION 0

5.8.12 RECORD the water tank level reading on the DTAM $31 "$

5.8.13 The next step will cause a low water level alarm on the DTAM.

5.8.14 VERY SLOWLY DECREASE the test manometer pressure until the "PIC WATER LEVEL LOW" (alarm 9) occurs on the DTAM. (This alarm should occur between 11.75 " to 12.75 " water gauge.)

5.8 .15 ACKNOWLEDGE the alarm at the DTAM.

5.8 .16 RECORD the manometer pressure and the DTAM water level readings.

Pressure on manometer Water Level on DTAM

5.8.17_SLOWLY INCREASE the manometer pressure until the alarm clears on the DTAM. (This should occur at approximately 15.5 "water gauge.)

5.8.18_RECORD the manometer pressure and the DTAM water level readings.

Pressure on manometer Water Level on DTAM

5.8 .19 ENSURE the "PIC Water" alarm indicates "norm".

5.8 .20 REMOVE the test manometer from the SALW-LT-6003N high pressure vent/test port and reinstall the vent plugs on both the high and low sides.

5.8.21_ OPEN valve SALW-V-6029N located in the Water Cabinet.

5.8.22_OPEN valve SALW-V-6031N located in the Water Cabinet.

5.8.23 ___ ENSURE "Water Tank" reading on the DTAM shows a value in inches.

Record the reading

\section{WEIGHT FACTOR TEST}

5.8.24_CONNECT a test manometer pressure source that can output at least 125 " water gauge to the HIGH PRESSURE dip tube on the side of the WFIE Cabinet.

5.8.25_ENSURE SALW-V-6001N is CLOSED.

5.8.26___ ENSURE SALW-V-6005N is OPEN. 
ENSURE SALW-V-6006N is OPEN.

5.8.29_ENSURE SALW-WFT-6002N EQUALIZING valve located on the SALW-V-6036N 3-Valve manifold in the WFIE cabinet is CLOSED.

5.8.30_ENSURE the LOW and HIGH side isolation valves located on the SALW-V-6036N 3-Valve manifold in the WFIE cabinet are OPEN.

5.8.31 SET the test manometer to 125 " (+/-1") water gauge. Record the manometer reading.

5.8.32 RECORD the "WFT" reading on the DTAM. The reading is to be 125 " $(+/-5$ ').

5.8.33_BLEED off the pressure on the test manometer. Leave connected for testing the specific gravity transmitter.

5.8.34_CLOSE SALW-V-6006N.

5.8.35_OPEN SALW-WFT-6002N equalizing valve located on SALW-V$6036 \mathrm{~N} 3$-Valve manifold in the WFIE cabinet.

5.8.36_CLOSE the LOW and HIGH side isolation valves located on the $\overline{\text { SALW }}$-V-6036N 3-Valve manifold in the WFIE cabinet.

\section{SPECIFIC GRAVITY TRANSMITTER}

5.8.37_ ENSURE SALW-V-6007N is OPEN.

5.8.38_ENSURE SALW-V-6005N is OPEN.

5.8.39 ENSURE the LOW and HIGH side isolation valves located on SALW$\overline{V-6035 N} 3-V$ alve manifold in the WFIE cabinet are OPEN.

5.8.40___ ENSURE the specific gravity transmitter equalizing valve located on the SALW-V-6035N 3-Valve manifold located in the WFIE cabinet is CLOSED. SET the test manometer to 5"water gauge $(+/-0.3$ "). 
RPP-5489

REVISION 0

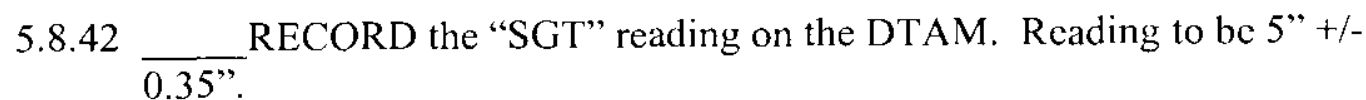

5.8.43___ BLEED off pressure on the manometer.

5.8.44_ENSURE "SGT LOW” alarm occurs (alarm 13).

5.8.45_ACKNOWLEDGE the alarm.

5.8.46___ DISCONNECT the test manometer.

5.8.47_CLOSE SALW-V-6007N.

5.8.48_CLOSE SALW-V-6005N.

5.8.49_OPEN SALW-SGT-6001N equalizing valve located on SALW-V$\overline{6035 \mathrm{~N}} 3$-Valve manifold in the WFIE cabinet.

5.8.50_CLOSE the LOW side and HIGH side isolation valves located on SALW-V-6035N 3-Valve manifold in the WFIE cabinet.

\section{FLOW METER SIGNAL CHECK}

5.8.51_IF necessary, ENSURE a brain terminal is connected to flow converter

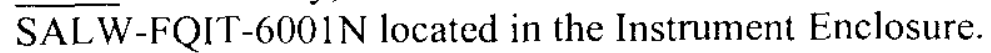

5.8.52_SIMULATE a flow signal of $4.0 \mathrm{gpm}(50 \% \mathrm{span})$ with the hand-held brain terminal or from the flow converter face switches.

5.8.53 RECORD the flow readings on the front of the flow converter and on the DTAM (PMP FLOW). Readings to be $4.0+/-0.4 \mathrm{gpm}$.

Flow converter DTAM (PMP FLOW)

5.8.54_RESTORE the flow converter, SALW-FQIT-6001N to its original configuration. 
RPP-5489

REVISION 0

\section{SUCTION AND DISCHARGE PRESSURE SIGNAL}

5.8.55 ENSURE a current source is connected to PSPT + and PSPT- on the intrinsic side terminal board in the Intrinsic Safe panel. Set the source to "transmitter simulate."

5.8.56_SET the current source to approximately $4 \mathrm{~mA}$ and record the suction pressure reading on SALW-PI-6012N. Reading to be approximately zero. psi

5.8.57_SET the current source to approximately $20 \mathrm{~mA}$ and record the suction pressure reading on SALW-PI-6012N. Reading to be approximately 100psi. psi

5.8.58_DISCONNECT the current source.

5.8.59 ENSURE a current source is connected to PDPT+ and PDPT- at the intrinsic side terminal board in the Intrinsic Safe pancl. Set the source to transmitter simulate.

5.8.60_ SET the current source to approximately $4 \mathrm{~mA}$ and record the discharge pressures on SALW-PI-6011N and on the DTAM. Readings should be approximately zero.

SALW-PI-6011N_p_ psi DTAM (PMP DISC) psi

5.8.61_SET the current source to approximately $20 \mathrm{~mA}$ and record the discharge pressures on SALW-PI-6011N and on the DTAM. Readings should be approximately 300 psi.

SALW-PI-6011N_p_ psi DTAM (PMP DISC) psi

5.8 .62 DISCONNECT the current source.

\section{PIT FLAMMABLE GAS MONITOR ANALOG SIGNAL TO PICC}

5.8.63 ENSURE a current source is connected to terminal board TB1 in the Instrument Enclosure, points FGM $0(+)$ and FGM $0(-)$

5.8.64___ SET the current source to approximately $4 \mathrm{~mA}$. 
RPP-5489

REVISION 0

5.8.65_RECORD the "FGM" percent reading from the DTAM. Reading is to be approximately zero. $\%$

5.8.66___ SET the current source to approximately $10 \mathrm{~mA}$.

5.8.67_ RECORD the "FGM" percent reading from the DTAM. Reading is to be approximately $11 \%$. $\%$

$5.8 .68 \_$SET the current source to approximately $20 \mathrm{~mA}$.

5.8.69_RECORD the "FGM" percent reading from the DTAM. Reading is to be approximately $30 \%$. $\%$

5.8.70_ DISCONNECT the current source.

\section{DOME SPACE FLAMMABLE GAS MONITOR ANALOG SIGNAL TO PLC}

5.8.71_ENSURE a current source is connected to terminal board TB1 in the Instrument Enclosure, points FGM 1(+) and FGM 1(-)

5.8.72_SET the current source to approximately $4 \mathrm{~mA}$.

5.8.73 RECORD the "FGM" percent reading from the DTAM. Reading is to be approximately zero. $\%$

5.8.74__ SET the current source to approximately $10 \mathrm{~mA}$.

5.8.75_RECORD the "FGM" percent reading from the DTAM. Reading is to be approximately $11 \%$. $\%$

5.8.76__ SET the current source to approximately $20 \mathrm{~mA}$.

5.8.77_RECORD the "FGM" percent reading from the DTAM. Reading is to be approximately $30 \%$. $\%$

5.8.78__ DISCONNECT the current source.

\section{THERMOCOUPLE INPUTS TO THE PLC}

5.8.79_WARM thermocouple SALW-TE-6004N located in the Instrument Enclosure.

5.8.80__ ENSURE the "PLC CAB temp" on the DTAM displays a temperature change. 

CONTINUE to warm the thermocouple until "PLC Enclosure HI" (alarm 10) occurs. This will be approximately 130 degrees F. ACKNOWLEDGE the alarm.

5.8.83 ENSURE "PLC CAB temp" on the DTAM shows a temperature DECREASE after the heat source is removed from the SALW-TE-6004N thermocouple.

5.8.84_ENSURE the "PLC temp" alarm returns to "norm" when the temperature decreases below 125 degrees $\mathrm{F}$.

5.8.85 WARM thermocouple SALW-TE-6003N located in the Air Compressor Cabinet.

5.8.86_ENSURE the "COMPRS temp" on the DTAM displays a temperature change.

5.8.87_CONTINUE to warm the thermocouple until "Air Compressor Temp HI" (alarm 11) occurs. This will be approximately 130 degrees F.

5.8.88_ACKNOWLEDGE the alarm.

5.8.89_ENSURE "COMPRS temp" on the DTAM shows a temperature DECREASE after the heat source is removed from the SALW-TE-6003N thermocouplc.

5.8.90_ENSURE the "CMPRSR temp" alarm returns to "norm" when the temperature decreases below 125 degrees $F$.

5.8.91_COOL the thermocouple probe in the WFIE cabinet with such as ice water or cool air spray. Temperature needs to drop below 35 degrees $F$.

5.8.92_ENSURE alarm 30, "WFIE CAB Temp Low" occurs at the DTAM.

5.8.93 WARM or ALLOW to warm the thermocouple probe in the WFIE cabinet and ENSURE the "WFIE CAB Temp" alarm is "norm".

5.8.94_COOL the thermocouple probe in the Water cabinet with such as ice water or cool air spray. Temperature needs to drop below 35 degrees $\mathrm{F}$.

5.8.95_ENSURE alarm 25, "WATER CAB Temp Low" occurs at the DTAM.

5.8.96 WARM or ALLOW to warm the thermocouple probe in the Water cabinet and ENSURE the "WATER CAB Temp" alarm is "norm". 
RPP-5489

REVISION 0

5.8.97___ CONNECT a temperature simulator to the intrinsic side of the top thermocouple module (MTL 3081) in the Intrinsic Safe pancl.

5.8.98_ SET the temperature simulator to approximately 140 degrees F.

5.8.99_ENSURE the "PUMP temp" reads approximately 140 degree at the DTAM.

5.8.100___ ENSURE the "Jmp Htr" is ON at the DTAM.

5.8.101___ DECREASE the temperature simulator to approximately 39 degrees or lower until alarm 8 "Pump/Jumper Temp Trouble" alarms on the DTAM.

5.8.102___ ACKNOWLEDGE the alarm.

5.8.103_ DISCONNECT the temperature simulator.

5.8.104_CONNECT a temperature simulator to the intrinsic side of the second thermocouple module (MTL 3081) in the Intrinsic Safe panel.

5.8.105_ SET the temperature simulator to approximately 140 degrees F.

5.8.106____ ENSURE the "JMPER TEMP" reads approximately 140 degree at the DTAM.

5.8.107_ENSURE the "Jmp Htr" is ON at the DTAM.

5.8.108___ENSURE the switch installed on TB4 between points "FGM" and "CKT5H-A" is in the CLOSED position.

5.8.109___ ENSURE approximately $120 \mathrm{vac}$ between HT-1 and CKT3-N at TB12.

5.8.110___ WHLE MONITORING the voltage at TB12, INCREASE the temperature to 206 degrees $F$ or higher until the voltage at TB12 goes to approximately zero.

5.8.111_WHILE MONITORING the voltage at TB12, decrease the temperature to 194 degrees F or lower until the voltage at TB12 goes to approximately $120 \mathrm{vac}$.

5.8.112_OPEN the switch on TB4 that is across "FGM" and "CKT5H-A".

5.8.113_ENSURE the voltage at TB12 goes to approximately zcro.

5.8.114___ CLOSE the switch on TB4 that is across "FGM" and "CKT5H-A". 
RPP-5489

REVISION 0

5.8.115_ENSURE the voltage at TB12 returns to approximately $120 \mathrm{vac}$.

5.8.116_TURN OFF the heat trace from the DTAM.

5.8.117_ ENSURE the voltage at TB12 goes to approximately zero.

5.8.118_ TURN ON the heat trace from the DTAM.

5.8.119___ ENSURE the voltage at TB12 returns to approximately $120 \mathrm{vac}$.

5.8.120_ INCREASE the temperature simulator to approximately 226 degrees or higher until alarm 8 "Pump/Jumper Temp Trouble" alarms on the DTAM.

5.8.121_ACKNOWLEDGE the alarm.

5.8.122_ DISCONNECT the temperature simulator.

5.8.123___ ENSURE the "JMPR HT" alarm returns to "norm" on the DTAM.

5.8.124Engineer to Ensure section 5.8 is completed and sign below.

Engineer Signature Date

5.8.125Quality Assurance Inspector to Verify that section 5.8 is complete and sign below.

Quality Assurance Inspector Signature Date 


\section{$5.9 \quad$ JET PUMP INTERLOCK CIRCUITS}

5.9.1 ENSURE the two leak detector probes, LS-1 and LS-2 proximity switches, the FGM switch at TB4, Dilution switch at TB4, and the Recirc switch at the Intrinsic Safe pancl are in place as per steps 5.8.1 to 5.8.7.

5.9 .2

IF POSSIBLE, CONNECT three current sources to the following points. One to JFPT + and JFPT-in the Intrinsic Safe panel at the intrinsic terminal board; one to RFPT + and RFPT - in the Instrument Enclosure at TB2; and one to PXPT+ and PXPT- at the intrinsic terminal board in the Intrinsic safe panel. Set the current sources to "transmitter simulate" and at $6 \mathrm{~mA}$. NOTE: If three current sources are not available, then software forces will be used during this section to bypass the inputs not being tested.

5.9.3_CONNECT the laptop computer to the PLC to set forces and observe logic when required.

\section{RECIRCULATION FLUSH PRESSURE SIGNAL TO PLC}

5.9.4_ENSURE a current source is connected to points RFPT+ and RFPT- in the Instrument Enclosure at TB2 and is set to approximately $6 \mathrm{~mA}$.

5.9.5 ENSURE the green light on the Instrument Enclosure and on the Jet Pump motor starter are ON.

5.9.6_ APPLY software forces to allow the jet pump to start. (Engineering will apply the forces from the laptop computer connected to the PLC.)

5.9.7_ TURN the selector switch on the Jet Pump Motor Starter to ON.

5.9.8_ START the jet pump from the DTAM and OBSERVE that the red lights at the Instrument Enclosure and motor starter come ON and the green lights at both locations turn OFF. 
SLOWLY INCREASE the current source output to approximately

$12.5 \mathrm{~mA}$ or until the pump shuts down after a 3 second delay. OBSERVE the following: (Acknowledge the alarms as necessary to observe all the alarms.) NOTE: The horn sound can be adjusted by turning the set screw on the front of the horn for sound level as directed by the engineer or PIC.

Record current reading on current source. $\mathrm{mA}$ The strobe light flashes and the horn sounds. Alarm 12 occurs, "JET PUMP SHUTDOWN". Alarm 39 occurs, "RECIRC FLUSH PRESS HI". Red lights at the motor starter and Instrument Enclosure are OFF. Green lights at the motor starter and Instrument Enclosure are ON. The "RECR FL PR" is approximately 15 psi. psi Ensure addresses N20:32/2 and N20:32/6 are actuated as observed on the laptop computer in ladder 5 .

5.9 .10 DECREASE the current source to approximately $4 \mathrm{~mA}$.

5.9.11___ENSURE the "Recirc Press" alarm at the DTAM returns to "norm".

5.9.12___ ENSURE address N20:32/6 clears as observed on the laptop.

5.9.13 D__ DECREASE the current source to zero.

5.9.14_ENSURE alarm 14, "RFPT SIGNAL LOSS ALARM" occurs.

5.9.15_ACKNOWLEDGE the alarm.

5.9.16____ ENSURE address N20:32/7 is actuated as observed on the laptop.

5.9.17_ INCREASE the current source to approximately $6 \mathrm{~mA}$.

5.9.18_ENSURE the "RFPT SIGNAL" alarm returns to "norm" on the DTAM.

5.9.19_ENSURE address N20:32/7 clears as observed on the laptop.

\section{JUMPER FLUSH PRESSURE SIGNAL TO PLC}

5.9.20_ENSURE a current source is connected to points JFPT + and JFPT- in the Intrinsic Safe panel intrinsic terminal board and is set to approximately $6 \mathrm{~mA}$.

5.9.21_ENSURE the green light on the Instrument Enclosure and on the Jet Pump motor starter are ON. 
5.9.23 START the jet pump from the DTAM and OBSERVE that the red lights at the Instrument Enclosure and motor starter come $O N$ and the green lights at both locations turn OFF.

5.9.24_ENSURE address N20:32/2 is clear as observed on the laptop.

5.9.25 SLOWLY INCREASE the current source output to approximately

$12.5 \mathrm{~mA}$ or until the pump shuts down after a 3 second delay. OBSERVE the following: (Acknowledge the alarms as necessary to observe all the alarms.)

Record current reading on current source. $\mathrm{mA}$ Alarm 12 occurs, "IET PUMP SHUTDOWN". Alarm 3 occurs, "Flush Pressure HI". Blue light at the Instrument Enclosure is $\mathrm{ON}$. Red lights at the motor starter and Instrument Enclosure are OFF. Green lights at the motor starter and Instrument Enclosure are ON. The "PS2 FL PR" is approximately 15 psi. psi The horn sounded and the strobe light flashed upon pump shutdown. Ensure address N20:32/5 is actuated as observed on the laptop.

5.9.26_DECREASE the current source to approximately $4 \mathrm{~mA}$.

5.9.27_ENSURE the "Flush Press" alarm at the DTAM returns to "norm".

5.9.28_ENSURE the blue light at the Instrument Enclosure turns OFF.

5.9.29___ ENSURE address N20:32/5 clears as observed on the laptop.

5.9.30_ DECREASE the current source to zero.

5.9.31_ENSURE alarm 16, "JFPT SIGNAL LOSS ALARM" occurs.

5.9.32_ACKNOWLEDGE the alarm.

5.9.33_ENSURE address N20:32/8 actuates as observed on the laptop.

5.9.34_INCREASE the current source to approximately $6 \mathrm{~mA}$.

5.9.35_ENSURE the "JFPT SIGNAL" alarm returns to "norm" on the DTAM.

5.9.36___ ENSURE address N20:32/8 clears as observed on the laptop. 
RPP-5489

REVISION 0

\section{TRANSFER PRESSURE INTERLOCK INPUT}

5.9.37_ENSURE a current source is connected to points PXPT + and PXPT- in the Intrinsic Safe panel intrinsic terminal board and is set to approximately $6 \mathrm{~mA}$.

5.9.38___ ENSURE the laptop computer is connected to the PLC and is "on-line".

5.9.31_ENSURE the green light on the Instrument Enclosure and on the Jet Pump motor starter are ON.

5.9.32 APPLY software forces to allow the jet pump to start. (Engineering will apply the forces from the laptop computer connected to the PLC.)

5.9.33_ START the jet pump from the DTAM and OBSERVE that the red lights at the Instrument Enclosure and motor starter come $O N$ and the green lights at both locations turn OFF.

5.9.34___ DECREASE the current source to approximately $4.8 \mathrm{~mA}$ or until Timer

4.1 on the ladder logic of the PLC (rung 0 of ladder 5) starts timing.

5.9.35_ENSURE the amber light on the Instrument Enclosure turns ON immediately after the timer starts.

5.9.36_ENSURE after 30 seconds, the following occurs: (Acknowledge alarms as necessary to view all the alarms.)

"XFR Pressure LOW" (alarm 1) occurs at the DTAM. "JET PUMP SHUTDOWN" (alarm 12) occurs at the DTAM. Red lights at the motor starter and Instrument Enclosure are OFF. Green lights at the motor starter and Instrument Enclosure are ON. The horn sounded and the strobe light flashed upon pump shutdown.

5.9.37_INCREASE the current source to approximately $6 \mathrm{~mA}$ to clear the low pressure alarm.

5.9.38_ENSURE the "XFR Pressure" alarm is "norm" on the DTAM.

5.9.39_ START the pump from the DTAM.

5.9.40 INCREASE the current source to approximately $11.5 \mathrm{~mA}$ or until Timer

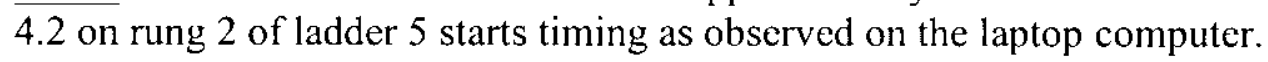


5.9.41_ENSURE after a 3 second delay, the following occurs: (Acknowledge alarms as necessary to view all the alarms.)

"XFR Pressure HIGH" (alarm 2) occurs at the DTAM. "JET PUMP SHUTDOWN" (alarm 12) occurs at the DTAM. Red lights at the motor starter and Instrument Enclosure are OFF. Green lights at the motor starter and Instrument Enclosure are ON. The horn sounded and the strobe light flashed upon pump shutdown.

5.9.42_ DECREASE the current source to approximately $6 \mathrm{~mA}$.

5.9.43_ENSURE the "XFR Pressure" alarm indicates "norm" on the DTAM.

\section{JR-1 VALVE POSITION INPUT (LS-1 AND LS-2)}

5.9.44_ START the pump from the DTAM.

5.9.45_REMOVE the metal from the front face of LS-1.

5.9.46 ENSURE the following occurs immediately: (Acknowledge alarms as necessary to view all the alarms.)

"JR-1 Position NON-PROCESS" (alarm 5) occurs at the DTAM. "JET PUMP SHUTDOWN" (alarm12) occurs at the DTAM. Red lights at the motor starter and Instrument Enclosure are OFF. Green lights at the motor starter and Instrument Enclosure are ON. The horn sounded and the strobe light flashed upon pump shutdown. Address N20:32/0 on ladder 5 is actuated as observed on the laptop.

5.9.47_ REMOVE the metal form the front face of LS-2.

5.9.48___ENSURE the "JR-1" still indicates "NON-PROCESS" at the DTAM.

5.9.49_ENSURE address N20:32/1 is actuated on ladder 5 as observed on the laptop.

5.9.50 REPLACE the metal in front of LS-1 and LS-2.

5.9.51_ENSURE the "JR-1" indicates "norm" on the DTAM and addresses $\mathrm{N} 20: 32 / 0$ and $\mathrm{N} 20: 32 / 1$ are clear on ladder 5 as observed on the laptop.

\section{FLAMMABLE GAS MONITOR INTERLOCK INPUT}

5.9 .52 START the pump from the DTAM.

5.9.53_ OPEN the FGM switch at TB4. 
5.9.54_ENSURE the following occurs immediately: (Acknowledge alarms as necessary to view the alarms.)

"FLAMMABLE GAS HIGH" (alarm 22) occurs at the DTAM. "IET PUMP SHUTDOWN" (alarm12) occurs at the DTAM. Red lights at the motor starter and Instrument Enclosure are OFF. Green lights at the motor starter and Instrument Enclosure are ON. The horn sounded and the strobe light flashed upon pump shutdown.

5.9.55_CLOSE the FGM switch at TB4.

5.9.56 ENSURE the "FGM" alarm indicates "norm" at the DTAM.

5.9.57_START the pump from the DTAM.

5.9.58_OPEN the dilution switch at TB4 in the Instrument Enclosure.

5.9.58___ ENSURE the following occurs after a 5-minute delay: (Acknowledge alarms as necessary to view the alarms.)

"DILUTION TANK NO FLOW" (alarm 35) occurs at the DTAM. "JET PUMP SHUTDOWN" (alarm 12) occurs at the DTAM. Red lights at the motor starter and Instrument Enclosure are OFF. Green lights at the motor starter and Instrument Enclosure are ON. The horn sounded and the strobe light flashed upon pump shutdown.

5.9.59_CLOSE the dilution switch.

5.9.60___ ENSURE the "Dilution tk" alarm indicates "norm" on the DTAM.

\section{RECIRCULATION LOW FLOW}

5.9.61___ START the pump from the DTAM.

5.9.62_ OPEN the Recirculation switch at the Intrinsic Safe panel.

5.9.63 ENSURE the following occurs after a 3-second delay: (Acknowledge alarms as necessary to view the alarms.)

"Recirculation Failure" (alarm 21) occurs at the DTAM. "JET PUMP SHUTDOWN" (alarm12) occurs at the DTAM. Red lights at the motor starter and Instrument Enclosure are OFF. Green lights at the motor starter and Instrument Enclosure are ON. The horn sounded and the strobe light flashed upon pump shutdown. 


\section{LEAK DETECTION INTERLOCK}

5.9.66_ENSURE there is a water supply and bucket available to actuate the leak detector probes. START the pump from the DTAM. PLACE the primary leak detector probe in a bucket of water. ENSURE the following occurs after a 3-second delay: (Acknowledge alarms as necessary to view the alarms.) "PUMP PIT LEAK" (alarm 6) occurs at the DTAM. "JET PUMP SHUTDOWN" (alarm12) occurs at the DTAM. Red lights at the motor starter and Instrument Enclosure are OFF. Green lights at the motor starter and Instrument Enclosure are ON. The horn sounded and the strobe light flashed upon pump shutdown. Ensure address N20:32/3 in ladder 5 actuates as observed on the laptop. REMOVE the leak detector probe from the bucket and allow the water to drain off.

5.9.71_ENSURE the "Pump Pit" leak alarm returns to "norm".

5.9.72___ENSURE address N20:32/3 clears as observed on the laptop.

5.9.73_ START the pump from the DTAM.

5.9.74_DISCONNECT one of the "SD" wires going to the primary leak detector probe.

5.9.75_ENSURE the following occurs after a 3-second delay: (Acknowledge alarms as necessary to view the alarms.) "PUMP PIT LEAK TROUBLE" (alarm 7) occurs at the DTAM. "JET PUMP SHUTDOWN" (alarm12) occurs at the DTAM. Red lights at the motor starter and Instrument Enclosure are OFF. Green lights at the motor starter and Instrument Enclosure are ON. The horn sounded and the strobe light flashed upon pump shutdown. Ensure address N20:32/3 actuates as observed on the laptop.

5.9.76_ RECONNECT the "SD" wire. 
RPP-5489

REVISION 0

5.9 .77 DTAM.

ENSURE the "Pump Pit" trouble alarm indicates "norm" on the

5.9.78___ ENSURE address N20:32/3 clears as observed on the laptop.

5.9.79_____ START the pump from the DTAM.

5.9.80_ PLACE the leak detector 1 probe in a bucket of water.

5.9.81_ENSURE the following occurs after a 3-second delay: (Acknowledge alarms as necessary to view the alarms.) the DTAM.

“LEAK DETECTOR NO 1 LEAK DETECTED” (alarm 18) occurs at "JET PUMP SHUTDOWN" (alarm12) occurs at the DTAM.

Red lights at the motor starter and Instrument Enclosure are OFF. Green lights at the motor starter and Instrument Enclosure are ON. The horn sounded and the strobe light flashed upon pump shutdown. Ensure address N20:32/4 actuates in ladder 5 as observed on the laptop.

5.9.82 REMOVE the leak detector probe from the bucket and allow the water to drain off.

5.9.83 ENSURE the "Leak 1" alarm returns to "norm".

5.9.84_ENSURE address N20:32/4 clears as observed on the laptop.

5.9.85_START the pump from the DTAM.

5.9.86_DISCONNECT one of the "SD" wires going to the leak detector 1 probe.

5.9.87_ENSURE the following occurs after a 3-second delay: (Acknowledge alarms as necessary to view the alarms.) DTAM.

"LEAK DETECTOR NO 1 TROUBLE" (alarm 19) occurs at the

"JET PUMP SHUTDOWN" (alarm 12) occurs at the DTAM.

Red lights at the motor starter and Instrument Enclosure are OFF. Green lights at the motor starter and Instrument Enclosure are ON. The horn sounded and the strobe light flashed upon pump shutdown. Ensure address N20:32/4 actuates as observed by the laptop.

$5.9 .88 \_$RECONNECT the "SD" wire. 
5.9.89_ENSURE the "Leak $1 \mathrm{ck}$ " alarm indicates "norm" on the DTAM.

5.9.90__ ENSURE address N20:32/4 clears as observed on the laptop.

5.9.91_DISCONNECT the current sources from the PXPT, RFPT and JFPT termination points.

5.9.92_DISCONNECT the test switches from the FGM, Dilution and Recirculation termination points.

5.9.93_DISCONNECT the proximity switches from the Intrinsic Safe panel.

5.9.94_REMOVE the laptop computer from the PLC.

5.9.95_ DISCONNECT the leak detector probes from the Instrument Enclosure.

5.9.96 Engineer to ENSURE section 5.9 is completed and sign below.

Engineer Signature $\quad$ Date

5.9.97 Quality Assurance Inspector to VERIFY that section 5.9 is completed and sign below.

Quality Assurance Inspector Signature Date 


\subsection{HEATERS, AIR CONDITIONER AND LIGHTS}

5.10.1_ TURN the heater ON in the air compressor cabinet. Set the thermostat high enough to allow the unit to operate.

5.10.2_ RESET the thermostat to approximately 40 degrees $F$ to allow the heat to turn OFF. Then unplug the heater.

5.10.3_TURN the fan thermostat switch to allow the fan in the air compressor cabinet to run.

5.10.4_RESET the fan switch to approximately 90 degrees $F$ to allow the fan to turn OFF.

5.10.5_TURN the heater ON in the WFIE cabinet. Set the thermostat high enough to allow the unit to operate.

5.10.6_RESET the thermostat to approximately 40 degrees $F$ to allow the heat to turn OFF. Then unplug the heater.

5.10.7_ TURN the heater ON in the Water cabinet. Set the thermostat high enough to allow the unit to operate.

5.10.8_RESET the thermostat to approximately 40 degrees $F$ to allow the heat to turn OFF.

5.10.9_ TURN the heater ON in the Instrument Enclosure. Set the thermostat high enough to allow the unit to operate.

5.10.10_ RESET the thermostat to approximately 40 degrees $F$ to allow the heat to turn OFF. Then unplug the heater.

5.10.11_ TURN the heater ON in the Locker. Set the thermostat high enough to allow the unit to operate.

5.10.12_RESET the thermostat to approximately 40 degrees $F$ to allow the heat to turn OFF. Then unplug the heater.

5.10.13_TURN ON the air conditioner in the Instrument Enclosure. If necessary, remove the front grill on the unit and adjust the temperature setting to get the unit to operate.

5.10.14_RESET the temperature setting on the air conditioner to between 90 to 95 degrees $F$. Remove the grill and filter on the front of the air conditioner for access to the adjustment. Then unplug the air conditioner. 
5.10.15_ENSURE the light in the WFIE cabinet operates.

5.10.16_ENSURE the light in the Instrument Enclosure operates.

5.10.17Engineer to ENSURE that section 5.10 is completed and sign below.

Engineer Signature Date

5.10.18Quality Assurance Inspector to VERIFY that section 5.10 is completed and sign below.

Quality Assurance Inspector Signature

Date 


\section{RPP-5489 \\ REVISION 0 \\ ACCEPTANCE TEST PROCEDURE}

This page may be reproduced as necessary

PAGE of

\begin{tabular}{|c|c|c|}
\hline \multicolumn{3}{|c|}{ ACCEPTANCE TEST PROCEDURE LOG } \\
\hline Name & Date & Comment \\
\hline & & \\
\hline & & \\
\hline & & \\
\hline & & \\
\hline & & \\
\hline & & \\
\hline & & \\
\hline & & \\
\hline & & \\
\hline & & \\
\hline & & \\
\hline & & \\
\hline & & \\
\hline & & \\
\hline
\end{tabular}


REVISION 0

\section{ACCEPTANCE TEST PROCEDURE EXCEPTION LOG}

This page may be reproduced as necessary

\section{ACCEPTANCE TEST PROCEDURE EXCEPTION LOG}

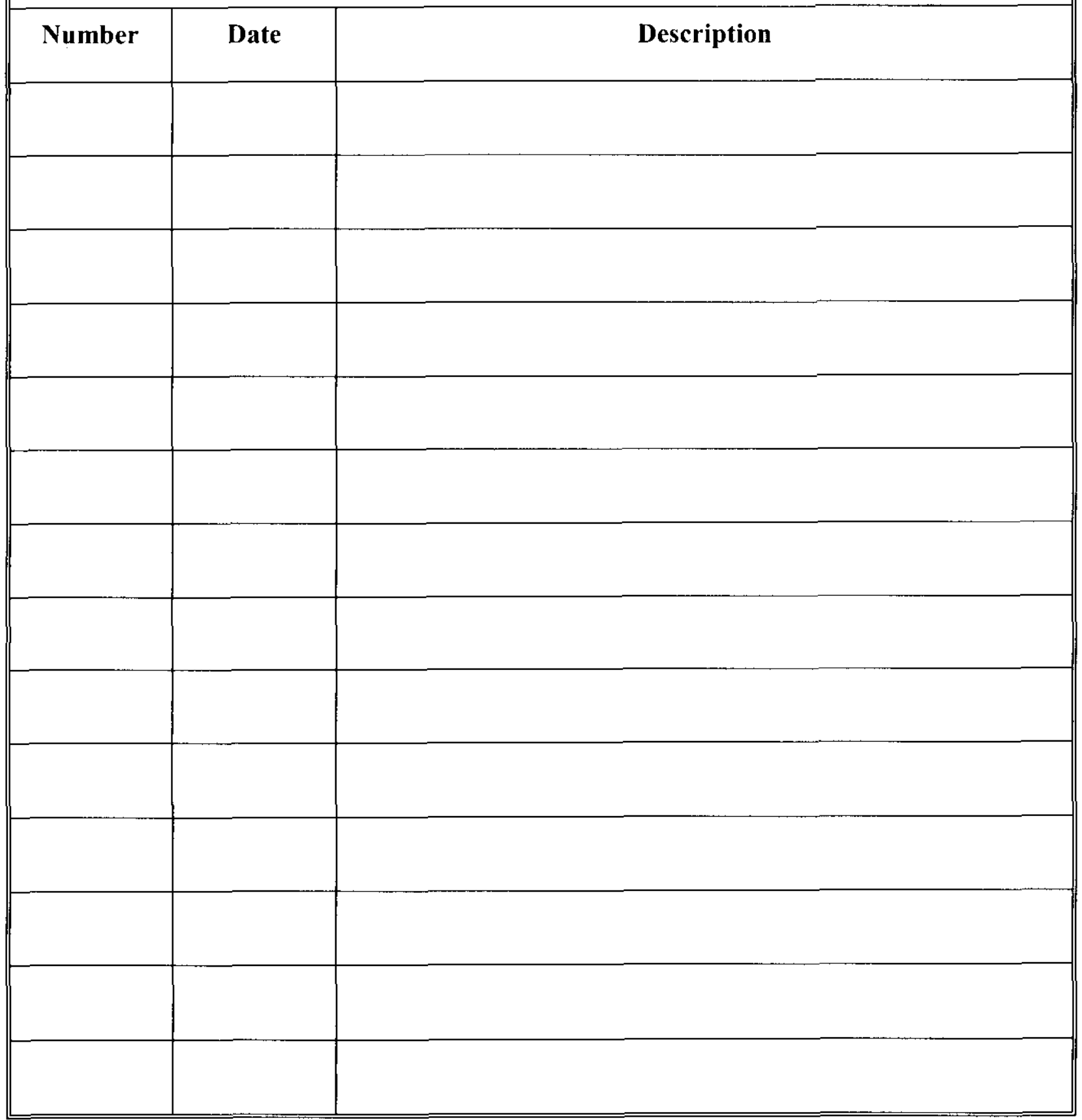




\section{ACCEPTANCE TEST PROCEDURE EXCEPTION RECORD}

This page may be reproduced as necessary.

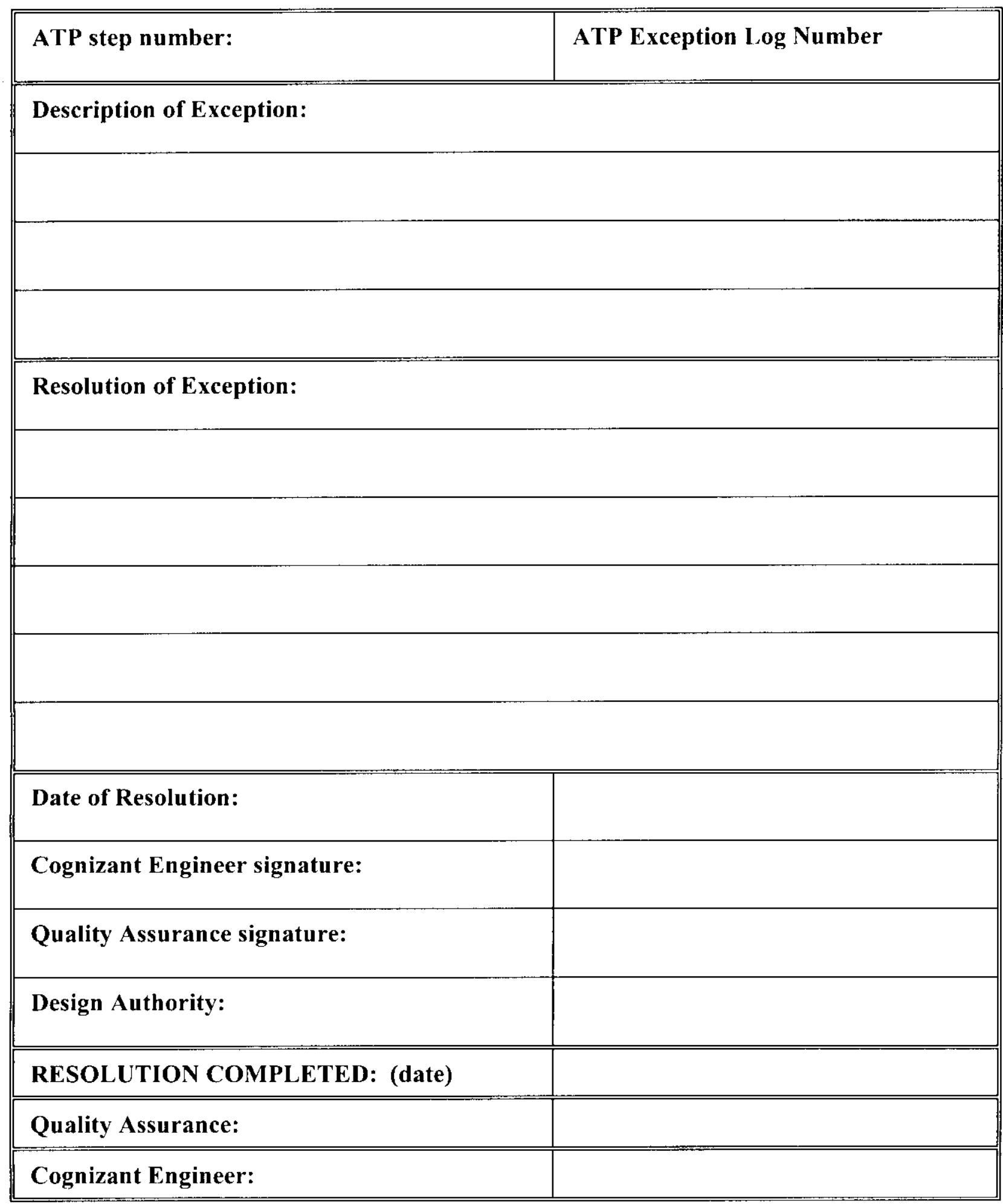


RPP-5489

REVISION 0

\section{ACCEPTANCE TEST PROCEDURE ACCEPTANCE RECORD}

This Acceptance Test Procedure has been completed and the results, including red-line changes, exceptions, and exception resolutions, have been reviewed for compliance with the intent of the Purpose (Section 1.0). The test results are accepted by the undersigned:

Cognizant Engineer (Signature)

(Print Name)

Date

Quality Assurance (Signature)

(Print Name)

Date 
RPP-5489

REVISION 0

\section{PROCEDURE PERFORMER SIGNATURE SHEET}

All personnel who will be performing, initialing and signing the procedure shall enter their printed name, signature and initials below.

\begin{tabular}{|c|c|c|}
\hline PRINT NAME & SIGNATURE & INITIALS \\
\hline & & \\
\hline & & \\
\hline & & \\
\hline & & \\
\hline & & \\
\hline & & \\
\hline & & \\
\hline & & \\
\hline & & \\
\hline & & \\
\hline & & \\
\hline & & \\
\hline & & \\
\hline & & \\
\hline & & \\
\hline & & \\
\hline & & \\
\hline & & \\
\hline & & \\
\hline
\end{tabular}


RPP-5489

REVISION 0

\section{PRE-JOB BRIEF SIGNATURE PAGE}

\begin{tabular}{|l|l|}
\hline PRINT NAME & SIGNATURE \\
\hline & \\
\hline & \\
\hline & \\
\hline & \\
\hline & \\
\hline & \\
\hline & \\
\hline & \\
\hline & \\
\hline
\end{tabular}

